\title{
Beden Eğitimi ve Spor Öğretmeni Adaylarının Fiziksel Aktiviteye Katılım Motivasyonlarının Bazı Değişkenlere Göre İncelenmesi
}

\author{
The Research Of Physical Education and Sport Teacher Candidates' Motivation In Physical \\ Activities Participation According To Certain Factors
}

\author{
Vahit Çiriş* - Turan Başkonuş ${ }^{* *}$
}

\begin{abstract}
The aim of this study is to describe the motivations of physical education and sports teacher candidates to participate in physical activity. 338 prospective teachers (147 females, 197 males) attending the different departments of Kırşehir Ahi Evran University School of Physical Education and Sports participated in the study on a voluntary basis. Screening method was used in the research. In the research, "Personal Information Form" and "Physical Activity Participation Motivation Scale" were used in the data collection process. When testing the research data, 0.05 significance level was taken. In the analysis of the data, the items related to the sub-problem were grouped and independent t-test and one-way variance analysis (ANOVA) with descriptive statistics such as frequency (f), percent $(\%)$, weighted average $(\overline{\mathrm{X}})$ and standard deviation (SD) were used. The source of the meaningful difference across the scale was examined with the Tukey test. The effect sizes of the significant difference observed in the scale and sub-dimensions were examined by eta square correlation coefficient. The results of the research showed that the motivation of physical education and sports teacher candidates to participate in physical activity is moderate. There was no significant difference in the variables of gender and departments on physical activity participation motivation of physical education and sports teacher candidates. Class level variable showed a significant difference in physical education and sports teacher candidates' motivation to participate in physical activity. The effect size of the meaningful difference across the scale is medium. The effect size of the significant difference observed in the environmental causes dimension is small, and the effect size of the meaningful difference observed in the causality dimension is medium.
\end{abstract}

\section{Structured Abstract: Introduction and Aim}

Physical activation has an important place for individuals of all ages in terms of protecting against the disease, having a better mood and helping to get rid of the diseases (Donnely, Blair, Jakicic, Manore, Rankin \& Smith, 2009; Edwards \& Thouros, 2006). One of the duties of education in bringing behavior to individuals is to mediate the promotion of sports in schools and encouraging students to participate in physical activity.

\footnotetext{
${ }^{*}$ Dr. Öğr. Üyesi, Kırşehir Ahi Evran Üniversitesi, Beden Eğitimi ve Spor Yüksekokulu, Beden Eğitimi ve Spor Eğitimi Dr. Lecturer, Kirşehir Ahi Evran Üniversity, School of Physical Education and Sports, Department of Physical Education and Sports

ORCID 0000-0002-3087-0942

vahitciris@gmail.com

** Dr., Milli Eğitim Bakanlığı, Kırşehir Milli Eğitim Müdürlüğü

Dr., Ministry of National Education

ORCID 0000-0001-8932-7656

baskonusturan@gmail.com

Cite as/ Atıf: Çiriş, V. \& Başkonuş, T. (2020). Beden eğitimi ve spor öğretmeni adaylarının fiziksel aktiviteye katılım motivasyonlarının bazı değişkenlere göre incelenmesi. Turkish Studies - Education, 15(4), 2483-2493. https://dx.doi.org/10.47423/TurkishStudies.43234

Received/Geliş: 29 April/Nisan 2020

Accepted/Kabul: 27 August/Ağustos 2020

Copyright $($ INTAC LTD, Turkey

Checked by plagiarism software

Published/Yayın: 30 August/Ağustos 2020

CC BY-NC 4.0
} 
(Yenal, Çamlıyer \& Saraçoğlu, 1999). One of the important factors in individuals doing sports is their motivation. Özgün, Yaşartürk, Ayhan and Bozkuş (2017) stated that motivation is an important factor for athletes to feel good and that the athlete will be successful due to this effect. As the teachers of the future, it is important for the students studying in physical education and sports schools to participate in physical activities and to make them a part of their daily lives, in terms of gaining this habit to their students they will raise. Based on this aim, this study has been prepared in order to determine the motivation of prospective teachers studying at Kırşehir Ahi Evran University School of Physical Education and Sports and to offer suggestions for the studies to be carried out to increase their participation in physical activity. In this context, it was examined whether the level of motivation of physical education and sports teacher candidates to participate in physical activity varies significantly according to the variable of gender, class level and the department they study.

\section{Method}

Although there are many types of non-experimental research, the best-known example is the screening type (Tabachnick \& Fidell, 2015). In this study also, scanning model was used. The accessible universe of the research is 843 prospective teachers studying at Kırşehir Ahi Evran University BESYO. 346 prospective teachers selected randomly from this universe constitute the study sample. Measuring instruments were delivered to 346 candidates and applied face to face. Volunteering was sought in filling the measurement tools. 8 of the measurement tools delivered was not included in the data analysis because of some reasons such as incorrect coding, being empty etc. And and the data obtained from a total of 338 candidates were evaluated. In the study, the personal information form created by the researchers and the Physical Activity Participation Motivation Scale developed by Tekkurşun-Demir and Cicioğlu (2018) were used.

\section{Results and Discussion}

According to the research data, the motivation of the candidates to participate in physical activity is generally at medium level. In their study, Demorco and Sidney (2003) found that students' level of participation in physical activity was low. Dagkas and Stathi (2007) in their study that they investigated the factors that affect adolescents' participation in physical activity found that their participation in physical activity is low. There are also studies in the literature that found that students' level of participation in physical activity was positive and high (Cheng, Cheng, Mak \&Wong, 2003; Green, Smith \& Roberts, 2003; Richard \& Lowry, 2009; Rasbery, Lee, Robin, Laris, Russell, Coyle \& Nihiser, 2011).

According to the study data, the motivation of candidates to participate in physical activity does not change according to their gender and the departments they study. In her study, Çiçek (2019) found that gender is not an effective variable in participation in physical activity. However, Beighle, Morgan, Le Masurier and Pangrazi (2006) found that male students participated in more physical activity than female students. In their study, Jhonston and Delga (2007) found female students' participation in physical activity at a low level, while male's stay in physical activity at a high level. Öztürk (2019) found that men participate more in physical activity. Coşkun (2019) found that male students have high levels of physical activity in his study on high school students. There are studies in the literature that differ from the results of the study and find that gender factor is in favor of women in participating in physical activity (Tekin, Tekin, Çalışır \& Bayrakdaroğlu, 2014; Ağaoğlu, 2015; Doğaner \& Balc1, 2017). In the results of this study, it can be said that the importance that women attach to the aesthetic appearance is effective in creating a difference in favor of women.

According to the research data, the motivation of the candidates to participate in physical activity varies according to the grade levels. In general, the average of the candidates studying in the 3rd grade is higher than the average of the candidates studying in the 1st, 2nd and 4th grades. In their study, Jhonston and Delga (2007) found that students attending lower classes have higher levels of participation in physical activity, and students attending final year have low levels of physical activity. In the literature, Doğaner and Balc1 (2017) found that, unlike the results of the study, 4th grade students love exercise and exercise more regularly. Yörük (2019) found that as the level of education increases, the participation of individuals increases.

\section{Conclusion and Suggestions}

According to the results of the research, the motivation of physical education and sports teacher candidates to participate in physical activity is generally at a medium level. Candidates' motivation to participate in physical activity varies significantly according to their grade levels. It is concluded that the average of the candidates studying in the 3rd and 4th grades are higher than the average of the candidates 
studying in the 1st and 2nd grades. Candidates' motivation to participate in physical activity does not differ significantly according to their gender and the departments they study. In this context, exercise programs can be made to increase the motivation of teacher candidates to participate in physical activity, applied hours of lessons can be increased to increase the motivation of physical activity of prospective teachers studying in the 1 st and 2nd grades, and the study can be renewed on a larger sample group with prospective teachers studying in other departments.

Key Words: Educational Sciences, Physical Education and Sports Teacher Candidate, Sports, Physical Activity, Motivation, Movement and Exercise.

Öz: $\mathrm{Bu}$ araştırmanın amacı beden eğitimi ve spor öğretmeni adaylarının fiziksel aktiviteye katılım motivasyonlarının betimlenmesidir. Araştırmaya Kırşehir Ahi Evran Üniversitesi Beden Eğitimi ve Spor Yüksekokulunun farklı bölümlerine öğrenim gören 338 öğretmen adayı (147 kadın, 197 erkek) gönüllük esasına göre katılmışlardır. Araştırmada tarama yöntemi kullanılmıştır. Araştırmada, veri toplama sürecinde "Kişisel Bilgiler Formu" ve "Fiziksel Aktiviteye Katılım Motivasyonu Ölçeği" kullanılmıștır. Araştırma kapsamında Kırşehir Ahi Evran Üniversitesinden 01.07.2020 tarih ve 2020/2 sayılı etik kurul izni alınmıştır. Araştırma verilerinin test edilmesinde 0.05 anlam düzeyi alınmıştır. Verilerin analizinde alt probleme ilişkin maddeler gruplandırılarak, frekans (f), yüzde (\%), ağırlıklı ortalama $(\bar{X})$ ve standart sapma (SS) gibi betimsel istatistiklerle birlikte bağımsız t-testi ve tek yönlü varyans analizi (ANOVA) kullanılmıștır. Ölçek genelinde görülen anlamlı farkın kaynağı Tukey testi ile incelenmiştir. Ölçek genelinde ve alt boyutlarda görülen anlamlı farklılığın etki büyüklükleri ise eta kare korelasyon katsayısı ile incelenmiştir. Araştırma sonuçları beden eğitimi ve spor öğretmeni adaylarının fiziksel aktiviteye katılım motivasyonlarının orta düzeyde olduğunu göstermiştir. Beden eğitimi ve spor öğretmeni adaylarının fiziksel aktiviteye katılım motivasyonları üzerinde cinsiyet ve okudukları bölüm değişkenlerinde anlamlı farklılık görülmemiştir. Sınıf seviyesi değişkeni beden eğitimi ve spor öğretmeni adaylarının fiziksel aktiviteye katılım motivasyonlarında anlamlı farklılık göstermiştir. Ölçek genelinde görülen anlamlı farklılığın etki büyüklüğü orta düzeydedir. Çevresel nedenler boyutunda görülen anlamlı farklılığın etki büyüklügü küçük düzeyde, nedensizlik boyutunda görülen anlamlı farklılığın etki büyüklüğü ise orta düzeydedir.

Anahtar Kelimeler: Eğitim Bilimleri, Beden Eğitimi ve Spor Öğretmeni Adayı, Spor, Fiziksel Aktivite, Motivasyon, Hareket ve Egzersiz.

\section{Giriş}

Günümüz de insanlar değişen koşullar ve teknolojik gelişmeler ile birlikte daha az hareket eder duruma gelmiş durumdadırlar. Çünkü çoğu insan gün boyu masa başı işlerde bilgisayar ile uğraşmakta, televizyon karşında ya da internette vakit geçirmekte ve bununla birlikte düzensiz beslenmektedir (Yıldırm, Akyol \& Ersoy, 2008). Dünya Sağlık Örgütü (WHO) genel olarak günlük minimum 30 dakika normal ve orta düzeydeki aktivitelerin bireylerin kardiyovasküler hastalık, diyabet ve bazı kanser türlerini azalttığını belirtmiştir (Smith, Banting, Eime, Sullivan \& Van Uffelen, 2017). Dünya Sağlı Örgütü bu tanımla bireyin fiziksel aktive ihtiyacının önemini vurgulamıştır. Bu vurgudan hareketle bireyin sağlığını korumaya yönelik günlük fiziksel aktivitenin öneminin ortaya konulabilmesi için fiziksel aktivite kavramının ne olduğuna bakılması gerekmektedir. Zorba (2010) fiziksel aktiviteyi, kaslar ve eklemlerin kullanımına bağlı enerji harcanmasındaki vücut hareketlerinin bütünü olarak tanımlarken, Scott (2008) ise kas sistemi ve vücut hareketleri ile enerji harcamak olarak tanımlamıştır. Bek (2008) ise fiziksel aktiviteyi, günlük hayatta yapılan bisiklet, yüzme, yürüme, mekik vb. vücut hareketlerinin tamamı şeklinde tanımlayarak fiziksel aktivitelerin günlük hayattaki önemini vurgulamıştır. Fiziksek aktivite, günlük yaşamda kasların ve eklemlerin hareket ettirilmesi sonucu ortaya çıkan enerji harcama miktarı olarak tanımlanmaktadır. Bu enerjinin harcanmasında fiziksel aktivitenin şiddeti ve sıklığı etken bir durumdur (Muthuri, 2014). Ayrıca düzenli yapılan egzersizlerin bireyin beden ve ruh sağlığ1 üzerinde bireyi hastalıklardan korumaya yönelik koruyucu etkisi olduğu bilinmektedir (Demir \& Filiz, 2004). Fiziksel aktive bireyin, haslıklara karşı korunma daha iyi bir ruh haline sahip olma ve 
hastalıklardan kurtulmaya yardımcı olması bakımından her yaştaki birey açısından önemli bir yere sahiptir (Donnely, Blair, Jakicic, Manore, Rankin \& Smith, 2009; Edwards \& Thouros, 2006).

Eğitimin bireylere davranış kazandırmadaki görevlerinden bir tanesi de okullarda sporun yaygınlaştırılması ve öğrencilerin fiziksel aktiviteye katılımlarının teşvik edilmesine aracılık etmektir (Yenal, Çamlıyer \& Saraçoğlu, 1999). Bireylerin spor yapmalarındaki önemli etmenlerden bir de motivasyon durumlarıdır. Türk Dil Kurumu [TDK] (2020) motivasyonu, isteklendirme veya güdüleme olarak açıklamıştır. Gömleksiz ve Serhatoğlu (2013) ise davranışın başlamasından bitimine kadar geçen sürede davranışın yönünü ve şiddetini açıklayan yapı olarak tanımlamışlardır. Özgün, Yaşartürk, Ayhan ve Bozkuş (2017) sporcuların kendilerinin iyi hissetmelerinde motivasyonun önemli bir etken olduğunu ve bu etkiye bağlı olarak sporcunun başarılı olacağını belirtmişlerdir. Geleceğin öğretmenleri olarak, beden eğitimi ve spor yüksekokullarında okuyan öğrencilerin fiziksel aktivitelere severek katılmaları ve günlük hayatlarını bir parçası haline getirmeleri yetiştirecekleri öğrencilere bu alışkanlığı kazandırma açısından önem arz etmektedir. $\mathrm{Bu}$ amaçtan yola çıkarak bu çalışma öğretmen adaylarının fiziksel aktiviteye katılım motivasyonlarını belirlemek ve onların fiziksel aktiviteye katılımlarının artırılmasına yönelik yapılacak çalışmalara öneriler sunabilmek açısından hazırlanmıştır. Çalışma sonuçlarının bu yönü ile alana katkı sağlayacağı düşünülmektedir. Bu kapsamda beden eğitimi ve spor öğretmeni adaylarının fiziksel aktiviteye katılım motivasyonlarının ne düzeyde olduğu, cinsiyet, sınıf düzeyi ve okudukları bölüm değişkenine göre anlamlı olarak farklılaşıp farklılaşmadığı incelenmiş̧tir.

\section{Yöntem}

Çalışmada tarama modeli kullanılmıştır. Araştırmada beden eğitimi ve spor öğretmeni adaylarının fiziksel aktiviteye katılım motivasyonlarının betimlenmesi amaçlanmıştır. Araştırmanın ikinci kısmında ise adayların fiziksel aktiviteye katılım motivasyonlarının cinsiyet, sınıf seviyesi ve okunan bölümlere göre değişip değişmediği incelenmiştir. Araştırma kapsamında Kırşehir Ahi Evran Üniversitesinden 01.07.2020 tarih ve 2020/2 sayılı etik kurul izni alınmıştır.

\section{Evren ve Örneklem}

Araştırmanın ulaşılabilir evreni Kırşehir Ahi Evran Üniversitesi BESYO'da öğrenim gören 843 öğretmen adayıdır. Bu evrenden, rastgele yolla seçilen 346 öğretmen adayı çalışma örneklemini oluşturmaktadır. Ölçme araçları 346 adaya ulaştırılmış ancak 338 adaydan elde edilen veriler değerlendirmeye alınmıştır. Örneklemindeki adaylarının bilgileri Tablo 1'de sunulmuştur.

Tablo 1: Örneklemindeki Adayların Demografik Bilgileri

\begin{tabular}{cccc} 
& & f & \% \\
\hline \multirow{2}{*}{ Cinsiyet } & Kadın & 141 & 41,7 \\
& Erkek & 197 & 58,3 \\
\hline \multirow{3}{*}{ Bölüm } & Ögretmenlik & 69 & 20,4 \\
& Antrenörlük & 157 & 46,4 \\
& Yöneticilik & 112 & 33,1 \\
\hline \multirow{3}{*}{ Sinıf } & 1. & 99 & 29,3 \\
& 2. & 103 & 30,5 \\
& 3. & 87 & 25,7 \\
& 4. & 49 & 14,5 \\
\hline & Toplam & 338 & 100 \\
\hline
\end{tabular}

Tablo 1 de çalışma örnekleminin \%41,7'sini (n=141) kadın adayları, \%58,3'ünü (n=197) ise erkek adayların oluşturduğu görülmektedir. Çalışma örneklemindeki adayların \%20,4'ü (n=69) öğretmenlik, \%46,4'ü $(n=157)$ antrenörlük, \%33,1'i $(n=112)$ ise yöneticilik öğrencisidir. Çalışma grubunda yer alan adayların \%29,3'ü (n=99) 1. sinıf, \%30,5'i (n=103) 2. sinıf, \%25,7'si (n=87) 3. sınıf ve \%14,5'i (n=49) ise 4. sınıf öğrencisidir. Çalışma grubunda yer alan adayların \%8'i $(n=27)$ az 
risk grubunda, $\% 47,6$ 's1 $(\mathrm{n}=161)$ risk, \%40,8'i $(\mathrm{n}=138)$ bağımlı grup ve \%3,6's1 $(\mathrm{n}=12)$ yüksek risk grubundadir.

\section{Veri Toplama Araçları}

Kişisel Bilgi Formu (KBF): Formda adayların tutumlarında farklılık oluşturabileceği düşünülen, cinsiyet, okudukları bölüm ve sınıf düzeyi değişkenleri yer almaktadır.

Fiziksel Aktiviteye Katılım Motivasyonu Ölçeği: Geçerlik ve güvenirlik çalışması Tekkurşun-Demir ve Cicioğlu (2018) tarafindan yapılan ölçek; 16 madde ve sirasıyla bireysel nedenler, çevresel nedenler ve nedensizlik olmak üzere 3 alt boyuttan oluşmaktadır. Ölçeğin Cronbach Alfa değerleri bireysel nedenler .89, çevresel nedenler .86, nedensizlik alt boyutunun ise .82 olarak belirlenmiştir. Çalışmamızda ise cronbach alfa değerleri; bireysel nedenler boyutu .83 , çevresel nedenler boyutu .73, nedensizlik alt boyutunun ise .87 olarak saptanmıştır. Ölçek 5'li likert şeklinde puanlanmakta ve "'1 kesinlikle katılmıyorum" ve "'5 kesinlikle kat1lyorum' 'u ifade etmektedir. Ölçekten alınabilecek en düşük puan 1, en yüksek puan 80'dir. Katılımcıların ölçekten yüksek puan almaları fiziksel aktiviteye katılım motivasyonlarının olumlu olduğu anlamına gelmektedir. Ölçeğin kullanım izni ve örneklem gruba uygun olup olmadığı ölçeği geliştiren çalışmacılardan Gönül Tekkurşun Demir'e sorulmuş ve bu görüş doğrultusunda ölçek örneklem gruba uygulanmıştır.

\section{Verilerin Toplanması}

Ölçme araçları adaylara araştırmacılar tarafından ulaştırılmış ve birebir uygulanmıştır.

\section{Verilerin Analizi}

Elde edilen veriler analiz için SPSS 20.0 paket programına yüklenmiştir. Araştırma verilerinin test edilmesinde 0.05 anlam düzeyi alınmıştır. Araştırmada frekans (f), yüzde (\%), ağırlıklı ortalama $(\overline{\mathrm{X}})$ ve standart sapma (SS) kullanılmıştır. Verilerin homojenliğine bakılmış ve normal dağılım gösterip göstermediği incelenmiştir. Normallik ile ilgili veriler Tablo 2 'de yer almaktadır.

Tablo 2:Normal Dağılım İle İlgili Bulgular

\begin{tabular}{|c|c|c|c|c|c|}
\hline & & & $\bar{X}$ & Çarpıklık & Basıklık \\
\hline \multirow{8}{*}{$\begin{array}{c}\text { Fiziksel } \\
\text { Aktiviteye } \\
\text { Katılım } \\
\text { Motivasyonu } \\
\text { Ölçeği }\end{array}$} & \multirow{2}{*}{ GENEL } & İstatistik & 3,13 &,- 029 &, 113 \\
\hline & & Standart hata & 0,027 & ,133 & ,265 \\
\hline & \multirow{2}{*}{ Bireysel } & İstatistik & 3,68 &,- 903 & ,832 \\
\hline & & Standart hata & 0,047 & ,133 & ,265 \\
\hline & \multirow{2}{*}{ Çevresel } & İstatistik & 3,44 &,- 281 &,- 123 \\
\hline & & Standart hata & 0,039 & ,133 & ,265 \\
\hline & \multirow{2}{*}{ Nedensizlik } & İstatistik & 2,38 & ,509 &,- 738 \\
\hline & & Standart hata & & ,133 & ,265 \\
\hline
\end{tabular}

Fiziksel aktiviteye katılım motivasyonu ölçeğinin çarpıklık $(-, 029)$ ve basılklk $(, 113)$ değerleri verilerin normal dağıldığını göstermektedir (Büyüköztürk, 2014; George \& Mallery, 2010). $\mathrm{Bu}$ kapsamda t-testi, ANOVA kullanılmıştır. Anlamlı farklılığın kaynağı Tukey testi ile belirlenmiştir. Anlamlı farklılığın etki büyüklügünü hesaplamak için ise eta-kare korelasyon katsayısı kullanılmıştır. Adayların ölçeklerde yer alan maddeler için verdikleri cevaplar beşli likert tipinde olup değerlendirme ölçeği grup değer aralığının tespitinde;a = Ranj / Yapılacak Grup Sayıs1 formülü kullanılmıştır (Taşdemir, 2003). Buna göre değerlendirme ölçeği şöyledir; 
Tablo 3:Ölçeklerin Puanlandırılması Verilen Ağırlık Nitelik Grupları Fiziksel Aktiviteye Katılım Ölçeği

\begin{tabular}{ccc}
\hline Verilen Ağılık & Nitelik grubu & Sınırı \\
\hline 5 & Kesinlikle Katıllıorum & $4.20-5.00$ \\
4 & Katıllyorum & $3.40-4.19$ \\
3 & Kararsızım & $2.60-3.39$ \\
2 & Katılımıorum & $1.80-2.59$ \\
1 & Kesinlikle Katıllmıyorum & $1-1.79$ \\
\hline
\end{tabular}

\section{Bulgular ve Yorum}

Fiziksel Aktiviteye Katılım Motivasyonları İle İlgili Betimsel İstatistikler

Tablo 4:Adayların Fiziksel Aktiviteye Katılım Motivasyonları

\begin{tabular}{ccccc}
\hline & $\mathrm{N}$ & $\overline{\mathrm{X}}$ & $\mathrm{SS}$ & Düzey \\
\hline Bireysel Nedenler Boyutu & 338 & 3,6805 &, 66825 & Katıllyorum \\
\hline Çevresel Nedenler Boyutu & 338 & 3,4448 &, 73156 & Kat1lıyorum \\
\hline Nedensizlik Boyutu & 338 & 2,3854 & 1,12958 & Katıllmıyorum \\
\hline Ölçek Geneli & 338 & 3,1343 &, 50941 & Kararsızım \\
\hline
\end{tabular}

Beden eğitimi ve spor öğretmeni adaylarının fiziksel aktiviteye katılım motivasyonları genel olarak kararsızım $(\overline{\mathrm{X}}=3,13)$ düzeyindedir. Adayların fiziksel aktiviteye katılım motivasyonları ölçeğin bireysel $(\overline{\mathrm{X}}=3,68)$ ve çevresel $(\overline{\mathrm{X}}=3,44)$ alt boyunlarında katılıyorum düzeyinde iken nedensizlik $(\overline{\mathrm{X}}=2,38)$ alt boyutunda ise katılmıorum düzeyindedir.

Fiziksel Aktiviteye Katılım Motivasyonları İle İlgili İlişkisel Bulgular

Tablo 5: Adayların Cinsiyetlerine Göre Fiziksel Aktiviteye Katılım Motivasyonlarına İlişkin T-

Testi Sonuçları

\begin{tabular}{|c|c|c|c|c|c|c|}
\hline & Cinsiyet & $\mathrm{N}$ & Mean & Std. Deviation & $\mathrm{t}$ & $\mathrm{p}$ \\
\hline $\begin{array}{c}\text { Bireysel Nedenler } \\
\text { Boyutu }\end{array}$ & $\begin{array}{l}\text { kadın } \\
\text { erkek }\end{array}$ & $\begin{array}{l}141 \\
197\end{array}$ & $\begin{array}{l}3,67 \\
3,68\end{array}$ & $\begin{array}{l}674 \\
, 665\end{array}$ &,- 156 & ,876 \\
\hline $\begin{array}{c}\text { Çevresel Nedenler } \\
\text { Boyutu }\end{array}$ & $\begin{array}{l}\text { kadın } \\
\text { erkek }\end{array}$ & $\begin{array}{l}141 \\
197 \\
\end{array}$ & $\begin{array}{l}3,50 \\
3,39\end{array}$ & $\begin{array}{l}, 761 \\
, 707 \\
\end{array}$ & 1,377 & , 169 \\
\hline Nedensizlik Boyutu & $\begin{array}{l}\text { kadın } \\
\text { erkek }\end{array}$ & $\begin{array}{l}141 \\
197 \\
\end{array}$ & $\begin{array}{l}2,35 \\
2,40\end{array}$ & $\begin{array}{l}1,171 \\
1,101\end{array}$ &,- 398 & ,691 \\
\hline Ölçek Geneli & $\begin{array}{l}\text { kadın } \\
\text { erkek }\end{array}$ & $\begin{array}{l}141 \\
197 \\
\end{array}$ & $\begin{array}{l}3,15 \\
3,12 \\
\end{array}$ & $\begin{array}{l}, 529 \\
, 495\end{array}$ &, 549 &, 583 \\
\hline
\end{tabular}

Tablo 5 incelendiğinde genel olarak kadın adayların $(\bar{X}=3,15)$ ortalamalarının erkek adayların $(\overline{\mathrm{X}}=3,12)$ ortalamalarından yüksektir. Bireysel ve nedensizlik alt boyutunda erkek adayların ortalamaları kadın adayların ortalamalarından yüksek iken çevresel alt boyutunda ise kadın adayların ortalamaları erkek adayların ortalamalarından yüksektir.

Öğretmen adaylarının fiziksel aktiviteye katılım motivasyonlarının cinsiyetlerine göre anlamlı olarak farklılaşıp farklılaşmadığını belirlemek için yapılan bağımsız örneklemler t testi sonucunda ölçek genelinde ve alt boyutlarda aradaki farkın anlamlı olmadığı bulunmuştur ( $p>.05$ ). Elde edilen bu bulgular adayların fiziksel aktiviteye katılım motivasyonlarının cinsiyetlerine göre değişmediğini göstermektedir. 
Tablo 6: Öğrenim Gördükleri Bölümlere Göre Fiziksel Aktiviteye Katılım Motivasyonlarınallişskin Sonuçlar

\begin{tabular}{cccc}
\hline & $\begin{array}{c}\text { Öğretmenlik } \\
(\bar{x})\end{array}$ & $\begin{array}{c}\text { Antrenörlük Eğitimi } \\
(\bar{x})\end{array}$ & $\begin{array}{c}\text { Spor Yöneticiliği } \\
(\bar{x})\end{array}$ \\
\hline Bireysel Nedenler Boyutu & 3,7343 & 3,6476 & 3,6935 \\
Çevresel Nedenler Boyutu & 3,5894 & 3,4533 & 3,3437 \\
Nedensizlik Boyutu & 2,4239 & 2,4061 & 2,3326 \\
Ölçek Geneli & 3,2148 & 3,1300 & 3,0908 \\
\hline
\end{tabular}

Tablo 6 incelendiğinde genel olarak beden eğitimi ve spor öğretmenliğinde okuyan adayların $(\overline{\mathrm{X}}=3,21)$ ortalamalarının antrenörlük eğitimi $(\overline{\mathrm{X}}=3,13)$ ve spor yöneticiliğinde $(\overline{\mathrm{X}}=3,09)$ okuyan adayların ortalamalarından yüksektir. Alt boyutlarda da öğretmenlik bölümünde okuyan adayların ortalamalarının antrenörlük ve yöneticilik bölümlerinde okuyan adayların ortalamalarından yüksek olduğu görülmektedir.

Adayların öğrenim gördükleri bölümlere göre fiziksel aktiviteye katılım motivasyonları ortalamalarının anlamlı olarak farklılaşıp farklılaşmadığının belirlenmesinde ANOVA kullanılmış ve sonuçlar Tablo 7 de sunulmuştur.

Tablo 7: Öğrencilerinin Öğrenim Gördükleri Bölümlere Göre Fiziksel Aktiviteye Katılım Motivasyonlarına İlişkin ANOVA Sonuçları

\begin{tabular}{ccccccc} 
& & KT & sd & KO & F & p \\
\hline \multirow{2}{*}{ Ölçek Geneli } & Gruplar aras1 &, 662 & 2 &, 331 & 1,278 &, 280 \\
& Gruplar içi & 86,788 & 335 &, 259 & & \\
\hline Toplam & 87,450 & 337 & & &, 648 \\
Bireysel & Gruplar arasi &, 389 & 2 &, 194 &, 434 & \\
Nedenler & Gruplar içi & 150,102 & 335 &, 448 & & \\
Boyutu & Toplam & 150,491 & 337 & & &, 088 \\
\hline Çevresel & Gruplar arasi & 2,597 & 2 & 1,299 & 2,447 & \\
Nedenler & Gruplar içi & 177,761 & 335 &, 531 & &, 829 \\
Boyutu & Toplam & 180,358 & 337 & &, 188 & \\
\hline Nedensizlik & Gruplar arasi &, 482 & 2 &, 241 & & \\
Boyutu & Gruplar içi & 429,513 & 335 & 1,282 & & \\
& Toplam & 429,995 & 337 & & & \\
\hline
\end{tabular}

Tablo 7'de gruplar arası ortalamaların istatistiksel olarak anlamlı derecede farklılaşmadığ 1 $(\mathrm{F}=1,278$ p>.05) görülmektedir. Alt boyutlarda da anlamlı farklılık ( $>$ >.05) görülmemektedir. Bu sonuçlar adayların fiziksel aktiviteye katılım motivasyonlarının okudukları bölümün değişkenine göre farklılaşmadığını göstermektedir.

Tablo 8:Adayların Sınıf Seviyelerine Göre Fiziksel Aktiviteye Katılım Motivasyonlarına İlişkin Sonuçlar

\begin{tabular}{ccccc}
\hline & $1 \cdot \sin 1 f(\bar{x})$ & $2 \cdot \sin 1 f(\bar{x})$ & $3 \cdot \sin ı f(\bar{x})$ & $4 \cdot \sin 1 f(\bar{x})$ \\
\hline Bireysel Nedenler Boyutu & 3,7710 & 3,5534 & 3,7126 & 3,7075 \\
\hline Cevresel Nedenler Boyutu & 3,4091 & 3,2896 & 3,6418 & 3,4932 \\
\hline Nedensizlik Boyutu & 2,1364 & 2,1966 & 2,6609 & 2,7959 \\
\hline Ölçek Geneli & 3,1047 & 2,9930 & 3,2743 & 3,2426 \\
\hline
\end{tabular}

Tablo 8'de genel olarak 3. sinıfta okuyan adayların $(\overline{\mathrm{X}}=3,27)$ ortalamalar1 1. $(\overline{\mathrm{X}}=3,10), 2$. $(\overline{\mathrm{X}}=2,99)$ ve 4. $(\overline{\mathrm{X}}=3,24)$ sinıfta okuyan adayların ortalamalarından yüksektir. Bireysel nedenler boyutunda en yüksek ortalamanın 1. sınıfta $(\bar{X}=3,77)$ okuyan adaylarda, en düşük ortalamanın ise 2 . sinıfta $(\overline{\mathrm{X}}=3,55)$ okuyan adaylarda; çevresel nedenler boyutunda en yüksek ortalamanın 3. sınıfta $(\overline{\mathrm{X}}=3,64)$ okuyan adaylarda, en düşük ortalamanın ise 2 . sinıfta $(\overline{\mathrm{X}}=3,28)$ okuyan adaylarda; 
nedensizlik boyutunda en yüksek ortalamanın 4. sınıfta $(\overline{\mathrm{X}}=2,79)$ okuyan adaylarda, en düşük ortalamanın ise 1. sınıfta $(\overline{\mathrm{X}}=2,13)$ okuyan adaylarda olduğu görülmektedir.

Öğretmen adaylarının öğrenim gördükleri sınıf seviyelerine göre fiziksel aktiviteye katılım motivasyonları ortalamalarının anlamlı olarak farklılaşıp farklılaşmadığının ANOVA kullanılmış ve sonuçlara Tablo 9'da yer verilmiştir.

Tablo 9:Adayların Sınıf Seviyelerine Göre Fiziksel Aktiviteye Katılım Motivasyonlarına İlişkin ANOVA Sonuçları

\begin{tabular}{|c|c|c|c|c|c|c|c|c|}
\hline & & KT & $\mathrm{sd}$ & KO & $\mathrm{F}$ & $\mathrm{p}$ & $\begin{array}{c}\text { Etki } \\
\text { Büyüklüğü }\end{array}$ & $\begin{array}{c}\text { Farkın } \\
\text { kaynağ1 }\end{array}$ \\
\hline Ölçek Geneli & $\begin{array}{c}\text { Gruplar aras1 } \\
\text { Gruplar içi } \\
\text { Toplam }\end{array}$ & $\begin{array}{c}4,423 \\
83,027 \\
87,450\end{array}$ & $\begin{array}{c}3 \\
334 \\
337\end{array}$ & $\begin{array}{c}1,474 \\
, 249\end{array}$ & 5,931 & 001 & .05 & $\begin{array}{l}1,2<3 \\
2<4\end{array}$ \\
\hline $\begin{array}{l}\text { Bireysel } \\
\text { Nedenler } \\
\text { Boyutu }\end{array}$ & $\begin{array}{c}\text { Gruplar aras1 } \\
\text { Gruplar içi } \\
\text { Toplam }\end{array}$ & $\begin{array}{c}2,601 \\
147,890 \\
150,491\end{array}$ & $\begin{array}{c}3 \\
334 \\
337\end{array}$ & $\begin{array}{l}, 867 \\
, 443\end{array}$ & 1,958 & , 120 & & \\
\hline $\begin{array}{c}\text { Çevresel } \\
\text { Nedenler } \\
\text { Boyutu }\end{array}$ & $\begin{array}{c}\text { Gruplar aras1 } \\
\text { Gruplar içi } \\
\text { Toplam }\end{array}$ & $\begin{array}{c}6,096 \\
174,262 \\
180,358 \\
\end{array}$ & $\begin{array}{c}3 \\
334 \\
337 \\
\end{array}$ & $\begin{array}{c}2,032 \\
, 522\end{array}$ & 3,894 & 009, & .03 & $1,2<3$ \\
\hline $\begin{array}{c}\text { Nedensizlik } \\
\text { Boyutu }\end{array}$ & $\begin{array}{c}\text { Gruplar aras1 } \\
\text { Gruplar içi } \\
\text { Toplam }\end{array}$ & $\begin{array}{c}24,673 \\
405,322 \\
429,995\end{array}$ & $\begin{array}{c}3 \\
334 \\
337 \\
\end{array}$ & $\begin{array}{l}8,224 \\
1,214\end{array}$ & 6,777 & ,000, & .05 & $\begin{array}{l}1,2<3 \\
1,2<4\end{array}$ \\
\hline
\end{tabular}

Adayların fiziksel aktiviteye katılım motivasyonlarının sınıf seviyelerine göre incelendiğinde ölçek genelinde $(\mathrm{F}=5,931 \mathrm{p}<.05)$, çevresel nedenler $(\mathrm{F}=3,894 \mathrm{p}<.05)$ ve nedensizlik $(\mathrm{F}=6,777 \mathrm{p}<.05)$ boyutlarında istatistiksel olarak anlamlı derecede farklılaştığ 1 ; bireysel nedenler boyutunda ise istatistiksel olarak anlamlı derecede farklılaşmadığ $(\mathrm{p}>.05)$ görülmektedir. Ölçek genelinde görülen anlamlı farkl1lığın etki büyüklüğü orta düzeyde $\left(\eta^{2}=.05\right)$ olup toplam varyansın \% 5 'ünü açıklamaktadır. etki büyüklükleri ise küçük $\left(\eta^{2}=.03\right)$ ve orta $\left(\eta^{2}=.05\right)$ düzeydedir.

Gruplar arası ortalamalar incelendiğinde; ölçek genelinde ortalamalar arası anlamlı farklılığın 3. sinıfta okuyan adaylar ile 1. ve 2. sinıfta okuyan adaylar arasında 3. sinıfta okuyan adayların lehine; çevresel nedenler boyutunda 3. sınıfta okuyan adaylar ile 1. ve 2. sinıfta okuyan adaylar arasında 3. sinifta okuyan adaylar lehine; nedensizlik boyutunda 3. sinıfta okuyan adaylar ile 1. ve 2. sinifta okuyan adaylar arasinda 3. sinifta okuyan adaylar lehine, 4. sinifta okuyan adaylar ile 1. ve 2. sinıfta okuyan adaylar arasında 4. sınıfta okuyan adaylar lehine oluştuğu görülmektedir. Bu sonuç adayların fiziksel aktiviteye katılım motivasyonlarının sınıf seviyelerine göre değiştiğini göstermektedir.

\section{Sonuç, Tartışma ve Öneriler}

Araştırmada adayların fiziksel aktiviteye katılım motivasyonları genel olarak orta düzeyde olduğu sonucuna ulaşılmıştır. Demorco ve Sidney (2003) yapmış oldukları çalışmada öğrencilerin fiziksel aktiviteye katılım düzeylerinin düşük olduğu sonucunu bulmuşlardır. Dagkas ve Stathi (2007) ergenlerin fiziksel aktiviteye katılımlarını etkileyen faktörleri araştırdıkları çalışmalarında, bireylerin fiziksel aktiviteye katılım durumlarının düşük olduğu sonucunu bulmuşlardır. Ayrıca alan yazında öğrencilerin fiziksel aktiviteye katılım düzeylerinin olumlu ve yüksek olduğunu bulan çalışmalar da bulunmaktadır (Cheng, Cheng, Mak \& Wong, 2003; Green, Smith \& Roberts, 2003; Richard \& Lowry, 2009; Rasbery, Lee, Robin, Laris, Russell, Coyle \& Nihiser, 2011).

Çalışma sonuçlarına göre adayların fiziksel aktiviteye katılım motivasyonları cinsiyetlerine ve okudukları bölümlere göre değişmemektedir. Çiçek (2019) çalışmasında fiziksel aktiviteye katılımda cinsiyetin etkili bir değişken olmadığı sonucunu bulmuştur. Beighle, Morgan, Le Masurier ve Pangrazi (2006) çalışmalarında erkek öğrencilerin kız öğrencilerden daha fazla fiziksel aktiviteye 
katıldıkları sonucunu bulmuştur. Jhonston ve Delga (2007) yapmış oldukları çalışmada bayan öğrencilerin fiziksel aktiviteye katılımlarını düşük düzeyde bulurken, erkeklerin fiziksel aktiviteye kalımlarını yüksek düzeyde bulmuştur. Öztürk (2019) çalışmasında erkeklerin daha çok fiziksel aktiviteye katıldıkları sonucunu bulmuştur. Coşkun (2019) lise öğrencileri üzerinde yürütmüş olduğu çalışmasında erkek öğrencilerin katılımlarının yüksek düzeyde olduğu sonucunu bulmuştur. Alana yazında çalışma sonuçlarından farklılaşan ve fiziksel aktiviteye kalımda cinsiyet faktörünün bayanlar lehine olduğunu bulan çalışmalar bulunmaktadır (Tekin, Tekin, Çalışır \& Bayrakdaroğlu, 2014; Ağaoğlu, 2015; Doğaner \& Balcı, 2017) Bu çalışma sonuçlarında bayanlar lehine farkın oluşmasında bayanların estetik görünüme verdikleri önemin etkili olduğu söylenebilir.

Araştırma sonuçlarına göre adayların fiziksel aktiviteye katılım motivasyonları sınıf seviyelerine göre değişmektedir. Genel olarak 3. sınıfta okuyan adayların ortalamalarının 1., 2. ve 4. sinıfta okuyan adayların ortalamalarından yüksek olduğu görülmektedir. Jhonston ve Delga (2007) yapmış oldukları çalışmada alt sınıflarda öğrenim gören öğrencilerin katılımlarının yüksek, son sinıfta okuyan öğrencilerin ise fiziksel aktiviteye katılım düzeylerinin düşük olduğu sonucunu bulmuştur. Alan yazında Doğaner ve Balcı (2017) çalışma sonucundan farklı olarak 4. sınıf öğrencilerinin egzersizi sevdikleri ve daha düzenli egzersiz yaptıkları sonucunu bulmuşlardır. Yörük (2019) çalışmasında eğitim seviyesi arttıkça bireylerin egzersize katılımlarının arttı̆̆ sonucunu bulmuştur.

Araştırma sonuçlarından yola çıkarak şu öneriler sunulmaktadır;

Öğretmen adaylarının fiziksel aktiviteye katılım motivasyonlarını artırmaya yönelik egzersiz porgramları yapilabilir.

1.ve 2. sınıfta okuyan öğretmen adaylarının fiziksel aktivite motivasyonlarını artırmaya yönelik uygulamalı ders saati artırılabilir.

Çalışma diğer bölümlerde okuyan öğretmen adayları ile daha geniş bir örneklem gurubu üzerinde yenilenebilir

\section{Kaynakça}

Ağaoğlu, S. (2015). Kadın sağlı̆̆ ve egzersiz. Spor ve Performans Araştırmaları Dergisi, 6(2), 6772.https://doi.org/10.17155/spd.54125

Beighle, A., Morgan, C. F., Le Masurier, G., \& Pangrazi, R. P. (2006). Children'sphysical activity during recessand outside of school. Journal of School Health, 76(10), 516520.https://doi.org/10.1111/j.1746-1561.2006.00151.x

Bek, N. (2008). Fiziksel aktivite ve sağlı̆ıımı. Sağlık Bakanlığı Yayınları.

Büyüköztürk Ş, Çakmak E, Akgün Ö E, Karadeniz Ş., \& Demirel F. (2010). Bilimsel araştırma yöntemleri. Pegem A Akademi.https://doi.org/10.14527/9789944919289

Büyüköztürk, Ş. (2014). Sosyal bilimler için veri analizi el kitabı. 20. Bask1.Pegem Akademi.https://doi.org/10.14527/9789756802748

Cheng, K. Y., Cheng, P. G., Mak, K. T., \& Wong, S. H. (2003). Relationships of perceived benefits and barriersto physical activity, physical activity participation and physical fitness in Hong Kong femaleadolescents. Journal Of Sports Medicine And Physical Fitness, 43, 523-9.

Çiçek, E. D. (2019). Üniversite ögrencilerinin spora katılım ve spora yönelik tutumlarının incelenmesi (Adana ili örneği). [Yayımlanmamış yüksek lisans tezi]. Aksaray Üniversitesi Sosyal Bilimler Enstitüsü.https://doi.org/10.29157/etusbe.123 
Çoşkun, A. (2019). Ortaokul ve lise ögrencilerinin fiziksel aktivite düzeyleri ile yakın çevrede yürünebilirlik algllarının incelenmesi (Çanakkale İli Örneği). [Yayımlanmamış doktora tezi].İstanbul Gedik Üniversitesi, Sağlık Bilimleri Enstitüsü. https://doi.org/10.1501/sporm_0000000276

Dagkas, S., \& Stathi, A. (2007). Exploring social and environmenta lfactors affecting adolescents' participation in physicalactivity. European Physical Education Review, 13(3), 369384.https://doi.org/10.1177/1356336X07081800

DeMarco, T., \& Sidney, K. (1989). Enhancing children's participation in physicalactivity. Journal of School Health, 59(8), 337-340.https://doi.org/10.1111/j.1746-1561.1989.tb04739.x

Demir, M., \& Filiz, K. (2004). Spor egzersizlerinin insan organizması üzerindeki etkileri. Gazi Üniversitesi Kırşehir Eğitim Fakültesi Dergisi, 5, 109-114.

Doğaner, S., \& Balcı, V. (2017). Ankara üniversitesi öğrencilerinin serbest zamanlarında egzersize katılma sıklıkları ve nedenleri. SPORMETRE Beden Eğitimi ve Spor Bilimleri Dergisi, 15(3), 119-128.https://doi.org/10.1501/Sporm_0000000316

Donnelly, J. E., Blair, S. N., Jakicic, J. M., Manore, M. M., Rankin, J. W., \& Smith, B. K. (2009). American College of Sports Medicine Position Stand. Appropriate physical activity intervention strategies for weight loss and prevention of weight regain for adults. Medicine And Science In Sports And Exercise, 41(2), 459471.https://doi.org/10.1249/MSS.0b013e3181949333

Edwards, P., \& Tsouros, A. (2006). Kentsel çevrede fiziksel aktivite ve aktif yaşamın desteklenmesi, Bilimsel Kanitlar. Dünya Sağllk Örgütü.

George, D., \& M. Mallery (2010). SPSS for windows step by step: A simple guide and reference.17,0 update (10a ed.) Boston: Pearson.https://doi.org/10.4324/9780429056765

Gömleksiz, M. N., \& Serhatlığlu, B. (2013). Öğretmen adaylarının akademik motivasyon düzeylerine ilişkin görüşleri. Türkiye Sosyal Araştırmalar Dergisi, 17(3), 99127.https://doi.org/10.33206/mjss.515271

Green, K., Smith, A., \& Roberts, K. (2005). Young people and life long participation in sport and physical activity: a sociological perspective on contemporary physical education programmes in England and Wales. Leisurestudies, 24(1), 2743.https://doi.org/10.1080/0261436042000231637

Johnston, L. D., Delva, J., \& O'Malley, P. M. (2007). Sports participation and physical education in American secondary schools: current levels and racial/ethnic and socioeconomic disparities. American Journal Of Preventive Medicine, 33(4), S195S208.https://doi.org/10.1016/j.amepre.2007.07.015

Karasar, N. (2005). Bilimsel araştırma yöntemi. Nobel Yayın Dağıtım.

Lowry, R., Wechsler, H., Kann, L., \& Collins, J. (2001). Recent trends in participation in physical education among US high school students. Journal of School Health, 71(4), 145152.https://doi.org/10.1111/j.1746-1561.2001.tb01312.x

Muthuri, S. K., Wachira, L. J. M., Leblanc, A. G., Francis, C. E., Sampson, M., Onywera, V. O., \& Tremblay, M. S. (2014). Temporal trend sand corre lates of physicalactivity, sedentary behaviour, and physical fitness among school-aged children in Sub-SaharanAfrica: a systematic review. International Journal of Environmental Research And Public Health, 11(3), 3327-3359.https://doi.org/10.3390/ijerph110303327 
Özgün, A., Yaşartürk, F., Ayhan, B., \& Bozkuş, T. (2017). Hentbolcuların spora özgü başarı motivasyonu ve mutluluk düzeyleri arasındaki ilişkinin incelenmesi. Uluslararası Kültürel ve Sosyal Araşttrmalar Dergisi (UKSAD), 3(Special Issue 2), 8394.https://doi.org/10.26466/opus.575329

Öztürk, M. A. (2019). Üniversite öğrencilerinin rekreasyonel fiziksel aktivitelere katılım engellerinin karşılaştırılması. Gelecek Vizyonlar Dergisi, 3(1), 12-19.https://doi.org/10.29345/futvis.68

Rasberry, C. N., Lee, S. M., Robin, L., Laris, B. A., Russell, L. A., Coyle, K. K., \& Nihiser, A. J. (2011). The association between school-based physicalactivity, including physical education, and academic performance: a systematic review of the literature. Preventive Medicine, 52.https://doi.org/10.1016/j.ypmed.2011.01.027

Scott, S. (2008). Able bodies balance training. Human Kinetics.

Smith, G. L., Banting, L., Eime, R., O’Sullivan, G., \& Van Uffelen, J. G. (2017). The association between social support and physical activity in older adults: a systematic review. International Journal of Behavioral Nutritionand Physical Activity, 14(1), 56.https://doi.org/10.1186/s12966-017-0509-8

Tabachnick, B., G. \& Fidell, L., S. (2015). Using multivariatestatistics. (Çev. M. Baloğlu). Nobel (Orijinal bask1 tarihi, 2013)

Taşdemir, M. (2003). Eğitimde planlama ve değerlendirme. 2.Baskı. Ocak Yayınevi.

TDK (2020). Türkçe Sözlük. Motivasyon. https://sozluk.gov.tr/

Tekin, A., Tekin, G., Çalışır, M., \& Bayrakdaroğlu, S. (2015). Düzenli aerobik egzersiz programının üniversiteli obez kız ögrencilerin fiziksel, motorik ve psiko-sosyal parametrelerine etkisi. Spor ve Performans Araştırmalart Dergisi, 6(1), 1929.https://doi.org/10.17155/spd.42220

Yenal, T. H., Çamlıyer, H., \& Saracaloğlu, A. S. (1999). İlköğretim ikinci devre çocuklarında beden eğitimi ve spor etkinliklerinin motor beceri ve yetenekler üzerine etkisi. Gazi Beden Ĕgitimi ve Spor Bilimleri Dergisi, 4(3), 15-24.https://doi.org/10.1501/sporm_0000000160

Yıldırım, M., Akyol, A., \& Ersoy, G. (2008). Şişmanlık (obezite) ve fiziksel aktivite: Enerji dengesinin aktivite yönüne bir bakış. 1. Baskı. Sağlık Bakanlığı Yayını, 729.

Yörük, G. (2019). Farklı sosyo-ekonomik çevrelerde yaşayan bireylerin fiziksel aktivite davranışları ve yakın çevrede yürünebilirlik düzeylerinin incelenmesi. [Yayımlanmamış yüksek lisans tezi]. Çanakkale Onsekiz Mart Üniversitesi Sağlı Bilimleri Enstitüsü.https://doi.org/10.28979/comufbed.393122

Zorba, E. \& Saygın, Ö. (2013). Fiziksel aktivite ve fiziksel uygunluk. Fırat Matbaac1lik.https://doi.org/10.1501/sporm_0000000384 